\title{
Increases in Sex with Same-Sex Partners Across U.S. Cohorts Born 1920-1998: A Race-Gender Intersection
}

\author{
Emma Mishel, Paula England, Jessie Ford \\ New York University \\ Mónica L. Caudillo \\ University of Maryland
}

Feb 7, 2018 version.

\begin{abstract}
We examine change across U.S. cohorts born between 1920 and 1998 in their probability of having had sex with same-sex partners last year and since age 18. We explore how trends differ by gender, race and class background. We use data from the 1988-2016 General Social Surveys. We find steady increases across birth cohorts in the proportion of men and women who have had both male and female sexual partners since age 18. A key finding is a race-gender intersection: black men and women of all races had similar increases - increases which were much steeper than those observed for white men. We suggest that women's increase is rooted in a long-term asymmetry in gender change, in which nonconformity to gender norms in many arenas is more acceptable for women than men. As the increase for men is largest among black men-and this is the population most affected by the rise of mass incarceration-we suggest the latter may be a contributing factor.
\end{abstract}




\section{Increases in Sex with Same-Sex Partners Across U.S. Cohorts Born 1920-1998: A Race-Gender Intersection}

\section{INTRODUCTION}

Bias against those who are (or appear to be) lesbian, gay, or bisexual is still common in the U.S. (Herek 2008; Mishel 2016; O'Brien 2001; Pascoe 2007; Tilcsik 2011). Nonetheless, change is apparent: a gay rights movement is now decades old (Clendinen and Nagourney 2001), public opinion has moved steadily in a more tolerant direction since at least the 1990s (Ford and England 2016; Lewis 2015), and there are visible "gayborhoods" in many cities (Ghaziani 2014). In the summer of 2015 a landmark Supreme Court decision said that same-sex marriage must be legal throughout the land (Obergefell v. Hodges 2015).

Despite all this change, there has been little analysis of change across birth cohorts in the proportion of Americans having same-sex sex partners. To address this gap, our study seeks to answer the following questions: Has sex with same-sex partners increased among U.S. adults? Do trends differ for men and women? Do trends differ by race and socio-economic background? To examine these questions, we utilize data from the 1988 to 2016 General Social Surveys. Separately for men and women, we estimate logistic regression models that assess change across cohorts born between 1920 and 1998 in whether individuals report that they have had sex with both sexes, or with same-sex partners only, since age 18 . We ask the same question about sexual activity in the last year. Our models control for respondents' age, race, immigrant status, region, and social class background (measured by mother's education); thus we are able to identify trends 
that result, not from compositional change on these factors, but from behavioral change within groups defined by these factors.

To preview our results for whether sex with same-sex partners has increased among U.S. adults, we find monotonic increases across birth cohorts in women's experience with same-sex sex partners. Specifically, we find significant increases across birth cohorts in the proportion of women who have had sex since age 18 with both men and women, who have done the same in the last year, and who have had sex with only women in the last year. Men also showed a significant increase across birth cohorts in having had sex with both men and women since age 18, but the increase was less steep than those for women, and patterns for men were inconsistent across cohorts on the other measures. We speculate that cohort change for women has been more prominent than for men due to the asymmetry of the gender revolution; specifically, we argue that the social costs of any kind of gender nonconformity, which includes deviating from exclusive heterosexuality, decreased much more for women than men.

Another goal of our analysis is to ascertain whether change by birth cohort in having had sex with both men and women, net of compositional variables, differs by race or class background (measured by mother's education). We find that for women, cohort trends in same-sex sexual behavior are similar by race and class background. The story for men is very different; race interacts strongly with cohort, such that cohorts born in 1966-75, 1976-83, and 1984-98 showed significantly greater increases for black than white men in reporting sex with both men and women. The black men in these cohorts would have turned 20 after 1980, when incarceration rates were rising steeply and extremely high. We suggest that the dramatic rise in incarceration might lead to more 
increase in sex with same-sex partners. Because black men's incarceration rates rose

more steeply than those for whites (National Research Council 2014), we would expect to see a steeper increase for black men than white men in whether they have ever had sex with both sexes. But we would not expect a racial disparity in trends on the other measures, such as sex only with men. This is exactly what our analysis reveals.

\section{PAST RESEARCH ON CHANGE IN SEX WITH SAME-SEX PARTNERS ${ }^{1}$}

Below, we review results from previous studies that examine change in same-sex sexual behavior by period and by cohort. Given the familiar age-period-cohort problem, ${ }^{2}$ period change may arise from any combination of period and cohort effects, and the same is true for cohort change.

Change Across Periods. Several studies have examined changes in same-sex sexual behaviors by period. Anderson and Stall (2002) found an increase between 1988 to 2000 , from $1-2 \%$ to $3-4 \%$, in the percent of men who had had sex with a man in the last year. But they found no significant increase in the proportion having ever had sex with a man since age 18. They used data from the General Social Survey (hereafter GSS), and did not examine trends for women. Another study conducted by Turner et al. (2005) used the same 1988-2002 GSS data and found substantial increases in same-sex sexual behavior for women in the 1990s in whether women had sex with a same-sex partner in

\footnotetext{
${ }^{1}$ Throughout the paper, we use the term "other sex" rather than "opposite sex" when referring to women in relation to men, and men in relation to women. We reject the term "opposite sex" because men and women are not the opposite of each other. When referring to women reporting sex with women, and men reporting sex with men, we use the term "same-sex" to describe the sexual behavior. We acknowledge that these terms imply that there are only two sexes, an assumption increasingly questioned by those who see themselves as or recognize others as nonbinary. Yet for simplicity of analysis for this paper, we follow the same language framework used in questions from the NSFG, as it provided only "male" or "female" as the categories into which respondents could classify their sex or gender, and it asked only about "male" and "female" sex partners. Our analysis includes only those who identified themselves as men or women.

${ }^{2}$ The identification problem is present if age, period, and cohort are entered linearly. The problem can be avoided by grouping some or all of the variables, but then results are quite sensitive to the categories into which each of the three are grouped.
} 
the last year, the last 5 years, or ever. They found increases for men in same-sex activity in the last year, but they were much smaller than the increases for women. Twenge and colleagues (2016) used GSS data from 1988-2014 and found that the proportion having at least one same-sex sex partner since age 18 increased from 3.6 to $8.7 \%$ for women and from 4.5 to $8.2 \%$ for men. Furthermore, Butler (2005) also used the 1988-2002 GSS data, augmented by the 1992 National Health and Social Life Survey. She found increases from 1988-2002 in the percent of men and women who had sex with a same-sex partner in the previous year. Using a linear functional form for period, the rate of change was significantly larger for women than men. A more recent analysis by Copen et al. (2016) found an increase between the 2006-10 and the 2011-13 National Survey of Family Growth (NSFG) surveys in the proportion of women who reported same-sex contact, and in the proportion of both men and women who claimed a bisexual identity, but no change for men in terms of same-sex sex.

Taken as a whole, these studies, all of which focused on period trends centered on the 1990s and/or early 2000s, suggest increases for both sexes in sex with same-sex partners, with larger changes for women.

Change Across Birth Cohorts. Butler (2005), whose main analysis focused on period change, also provided descriptive information on change in having had a same-sex partner since age 18 across cohorts born between 1929 and 1982. She found significant increases for women, but not for men. These analyses, however, had no control for age, or other compositional covariates, and thus could be a function of period change or compositional demographic change. Turner et al. (2005), also mentioned above for their period analysis, examined the proportions of men and women reporting any same-sex 
partner since they were 18 and how it varied by cohort. For women, they found increases from $1.6 \%$ for the cohort born before 1920 to $6.9 \%$ for those born between 1970 and 1984, the most recent cohort they examined. They found no cohort change for men. However, this analysis on cohort change was from a model with no covariates, even for age. Furthermore, Twenge et al. (2016), also discussed above for their period analysis, argued that the upward change in having had sex with a same-sex partner identified in their GSS analysis was a period not a cohort effect. This conclusion is suspect given that the techniques they used, proposed by Yang and Land (2013), have been shown via simulation not to identify cohort trends in some cases where they exist in artificially generated data (Bell and Jones 2014). The only multivariate analysis of cohort change in sex with same-sex partners is a study by England, Mishel and Caudillo (2016), which used NSFG data. Among women, they found cohort increases in reports of bisexual identity, of sex with both sexes, and of sex with women only. They found no cohort trend for men on change in sexual orientation or sex with same-sex partners. The analysis of England et al. (2016) is limited to cohorts born between 1966 and 1995 and to adults under 45.

The present study builds on this past research by conducting a multivariate analysis of change by birth cohort in sex with same-sex partners. We use a dataset with a broader span of ages than studies using the NSFG, and a larger range of cohorts than any past studies have used.

\section{EXPLAINING CHANGE IN SEX WITH SAME-SEX PARTNERS}

We present several possible explanations for why we may see an increase in same-sex sexual behavior across birth cohorts. We are, unfortunately, unable to test 
between them; our contribution is more modest - to assess cohort trends in sex with same-sex partners and how they differ by gender, race, and class. However, prior research and theorizing that suggests explanations for change in sexual behavior will help us speculate about causes of the cohort changes we document.

Change in Social Attitudes and Laws. National opinion polls of Americans show continuously rising numbers for those who support marriage equality for same-sex couples (Gallup 2015; Pew Research Center 2015) and continuously rising numbers for the approval of homosexuality (Gallup 2012; Smith 2011). Similarly, analyses of data from the General Social Survey show that attitudes about same-sex sex have become steadily more accepting since 1990, with over half of respondents in 2014 reporting same-sex sex as not wrong (Ford and England 2016; See also Butler 2005:426; Anderson and Fetner 2008).

Laws have also changed in a direction more favorable to LGBT rights; in June of 2013, the federal government struck down the Defense of Marriage Act (DOMA), ruling that the government cannot deny benefits to married same-sex couples by states, and the recent U.S. Supreme Court ruling Obergefell v. Hodges (2015) granted same-sex couples the right to marry in any state across America. Forty-one bills outlawing hate crimes against gay individuals, 70 bills protecting same-sex parents, 160 non-discrimination bills, and 147 bills protecting gay youth were introduced in 2016 alone (HRC 2016).

Social attitudes about homosexuality in the U.S. changing to become more accepting, and laws changing to increasingly support lesbian, gay, bisexual, and transgender (LGBT) rights, may have made sex with same-sex partners more acceptable, and thus led to increases in same-sex sexual behavior across successive birth cohorts. 
The Gay Rights Movement. The gay rights movement may have contributed to increased same-sex sexual behavior by birth cohort as it gained momentum, made the lives of gay people more visible, and fought for the acceptance of gay rights. The Society for Human Rights, the earliest known gay rights organization, was formed in 1924, but few efforts were made to spark advocacy work supporting gays and lesbians until after World War II (Clendinen and Nagourney 2001). In 1951, the California Supreme Court ruled that it was illegal to shut down a venue simply because gay people were the primary customers, which inspired a national movement to safeguard gay spaces (Ghaziani 2014). Around the same time, in the early to mid-1950s, the first national gay and lesbian organizations were formed: Mattachine Society in 1950 and Daughters of Bilitis in 1955. Despite the 1951 court decision, police frequently raided gay bars to harass and sometimes arrest gay individuals, and in 1969, the Stonewall Riots occurred. Patrons fought back after local police raided the Stonewall Inn, a gay bar in the West Village of New York City, which lead to three days of riots. This event is often credited with starting the modern gay rights movement (Clendinen and Nagourney 2001). One success of the movement was seen when, in 1973, the American Psychiatric Association removed homosexuality from their list of mental illnesses (Eaklor and Summers 2009).

The Sexual Revolution. The sexual revolution is usually dated as extending through the 1960s and 1970s, coinciding with the rise of the feminist and civil rights movements, the Stonewall Riots, the Vietnam war, and a counter culture of "sex, drugs, and rock-and-roll” (Bailey 1997; Joyner and Laumann 2001; Robinson et al. 1991; Smith 1973; Wu et al. 2017). While most of the change involved an increase in heterosexual premarital sex, it also led some to challenge heteronormativity, and to have a more 
positive and tolerant evaluation of sex as a human activity in general (Smith 1973). As such, birth cohort analysis of transgressive sexual behavior in general—not just of samesex sexual behavior - may help us better understand when and why cohort changes in same-sex sexual behavior occurred.

For this, we turn to Wu et al. (2017), who use NSFG data to examine changes by birth cohort in premarital sex, specifically in whether women delayed sex until marriage or not. Using cohorts born between 1938 and 1985, they find that roughly half of women born in the late 1930s and early 1940s were already sexually active prior to marriage. Especially rapid increases in premarital sex were found among women born between 1942-43 and 1945-55. Subsequent cohorts experienced less rapid increases, and premarital sex reached a plateau of roughly $85 \%$ to $90 \%$ for those born after 1962 . This analysis suggests that change in sexual behavior may have been proceeding since cohorts born before the "baby boom," from 1945 to 1965 . Given these changes in what was at first transgressive heterosexual behavior, it is plausible that the sexual revolution also inspired cohort changes in increased same-sex sexual behavior.

Change in Life Trajectories of Young Adults. Rosenfeld (2007) has argued that sexuality and decisions about partners have been altered by the contemporary "age of independence," the increase in the amount of time that young adults typically live away from their parents before they marry. A longer period between moving out of the parental home and moving into marriage provides a time when young adults can make choices with less parental surveillance. Rosenfeld provides evidence that this was a factor in the rise of young adults living with same-sex and/or interracial partners since the 1960s. 
Rise of the Internet and Emergence of "Gayborhoods." Those seeking samesex partners are a numerical minority. Thus, sexual minorities, like others facing "thin markets" have flocked to the internet as a way to more easily find partners. Today, using the internet has become the predominant way that same-sex couples in the U.S. meet (Rosenfeld and Thomas 2012). Thus, it is possible that the internet played a role in increasing same-sex sexual behavior among Americans by simply allowing for more access to locate and meet gay partners.

Along the same lines, the proliferation of gay neighborhoods (called "gayborhoods" by Ghaziani 2014) may be associated with increases in same-sex sexual behavior by birth cohort. Such neighborhoods emerged after World War II. Gayborhoods granted people greater accessibility to meet other gay people and potential same-sex partners, and provided a safe space for same-sex couples to show affection publicly (Ghaziani 2014).

\section{DO TRENDS VARY BY GENDER?}

Past studies have found gender differences in trends, such that the increase in same-sex sexual behavior has been more pronounced among women. Butler (2005), Turner et al. (2005) and England et al. (2016) all suggest significant recent increases of same-sex sex across recent cohorts of women, but they find much less or even no cohort change among men. Why might we expect trends in same-sex sexual behavior to differ by gender?

Some scholars argue that there are fundamental differences between how men and women perceive and act on their sexuality (Diamond 2016). As an example of the evidence in favor of this view, some experimental studies show that women (both lesbian 
and heterosexual) show similar levels of genital arousal to sexual stimuli of both their "preferred" and "non-preferred" sex, while, by contrast, men's measured arousal is much better predicted by the sexual orientation with which they identify (Chivers et al. 2004). If, among those who identify as heterosexual, more women than men are aroused by depictions of sex between two members of their own sex, as Chivers et al. found, this might imply that women are more receptive than men to cultural changes that legitimize same-sex relationships. Here we offer a thesis about why there has been more change in sexual behavior for women than men that does not require positing any gender differences in how arousal relates to behavior or identity. However, the aforementioned gender differences could be an additional factor leading women to be more responsive than men to social changes that reduce the stigma associated with having same-sex partners. The explanation that we put forth here is that cohort change for women has been more prominent than for men due to the asymmetry of the gender revolution.

One basic aspect of the gender system is that people face social pressure to conform to what is expected of them as men or women, such as that men should be tough and women gentle. Conforming to gender norms also requires at least appearing to be heterosexual. Just as women violate gender norms by being executives or carpenters and men violate gender norms by being stay-at-home dads or nurses, both men and women violate gender norms by not appearing to be straight. Moreover, violating gender norms in the sexual realm is seen as negative and often has social costs (Watts 2015; Pascoe 2007).

A second aspect of the gender system is that activities or attributes associated with women tend to be valued less than those that are associated with men. As one 
example of this, jobs filled largely by women pay less than what you could expect them to pay based on their demands (Levanon, England and Allison 2009). As another example, being a soldier is associated with men, and parenting with women; the state provides a special health care plan for veterans of military service, but there is no analogue for mothers.

When we put these two aspects of the gender system together-that people face disapproval for violating gender norms, and that masculinity is more highly valued than femininity - it implies that men will lose more status by violating gender expectations than women will. When men violate gender norms, they are seen as more feminine; when women violate gender norms, they are seen as more masculine. Either may be met with social disapproval, but the stigma is greater for men's gender nonconformity precisely because it is seen as a movement toward a devalued status--femininity. This devaluation of femininity is presumably the reason that boys seen as effeminate are stigmatized much more than girls seen as boyish (Fine 1987; Pascoe 2007). When we add to this that one needs to appear straight to conform to gender norms, it implies that departures from exclusive heterosexuality are more stigmatizing for men than women. Experimental work by Watts (2015) has shown exactly this. Ethnographic research supports the conclusion as well; ridiculing someone by calling him a "fag" is common among male youth, but it is much less common to ridicule girls by calling them "dykes" (Pascoe 2007). Indeed, a recent analysis of Google searches shows that "Is my son gay?" or "Is my husband gay?" are much more common searches than "Is my daughter gay?" or "Is my wife gay?" suggesting that people are more concerned about men and boys being gay than women and girls being gay (Mishel and Caudillo 2017). The greatest stigma seems reserved for 
men who appear effeminate and identify as gay or engage in sex with same-sex partners, especially those being the receptive partner in anal sex. ${ }^{3}$

Thus, we suggest the following explanation of why there has been more increase in women's than men's departure from exclusive heterosexuality: Changes associated with the gender revolution sent the message that gender nonconformity was more acceptable than before, and, given that deviations from exclusive heterosexuality are seen as gender nonconforming, part of the implicit message was permission to have same-sex sexual relationships. But this message was received much more strongly by women than men, because the continued devaluation of whatever was seen as feminine meant that the gender revolution was largely a one-way street, not really seen as applicable to men. The social costs of any kind of gender nonconformity, including deviating from exclusive heterosexuality, thus decreased much more for women than men. Because of this asymmetry, we expect to find more increase in women's than men's departure from exclusive heterosexuality in our analyses.

\section{INTERSECTIONALITY: DO TRENDS VARY BY RACE OR CLASS BACKGROUND—FOR MEN OR WOMEN?}

As mentioned above, there has been little research on birth cohort trends in samesex sexual behavior. There has been even less that examines how such cohort trends differ by race or socio-economic status, and virtually none looking at intersections between gender and race or class. Below, we summarize previous research that helps

\footnotetext{
${ }^{3}$ An exception to this generalization is the set of ritualistic sexual practices between men who identify as straight discussed by Ward (2015) and Silva (2016). Yet, while the practices Ward and Silva identify may be seen as normal in some settings, the fact that the men they studied shun a gay or bisexual identity strongly suggests that men are stigmatized more than women for sex with same-sex partners or nonheterosexual identities, as experimental work by Watts (2015) has shown.
} 
shape our hypotheses about differences in cohort trends by race, class, or their interaction.

Differences in Trends by Class. Attitudes that are disapproving of homosexuality might keep some individuals from having sex with a same-sex partner; thus changing attitudes could affect behavior. Previous research shows that more highly educated individuals are less disapproving of homosexuality (Loftus 2001; Ohlander, Batalova and Treas 2005; Ford and England 2016). But what about whether trends differ by class? One study finds that the effect of education on attitudes towards homosexuality lessened over time as support for gay rights became more mainstream (Kozloski 2010). Inconsistent with this, Ford and England (2016) find that trends in attitudes toward homosexuality are similar by education, with a similar gap by education (such that the more educated are less likely to think "homosexuality is wrong") in every year. Given these conflicting findings, even if attitudes do affect behavior, it is unclear what differences by class in behavioral trends we should expect.

The only multivariate, cohort-focused analysis that examines how cohort trends in same-sex sexual behavior vary by class background is the study by England et al. (2016), which covered cohorts born from 1966 to 1995 . They used mother's education as a proxy for class background, and they did not find differences in trends by class for either men or women; the monotonic upward cohort trends occurred among women of all class backgrounds. For men, the study found no upward trend, and this did not differ by class background.

Differences in Trends by Race. Attitudinal research finds that the increasing tolerance of same-sex sex during the 1990s occurred among whites but very little change 
occurred among blacks (Battle and Bennett 2000; Lewis 2003; Loftus 2001). However, starting about 2000, while blacks continued to hold more negative views than whites, both groups moved strongly in a more tolerant direction in attitudes toward gays (Ford and England 2016). To the extent that individuals' sexual behavior is affected by their own attitudes, or by the attitudes of their typically racially segregated networks, this leads us to expect that increases in same-sex sexual behavior occurred later among blacks than other groups.

As with analysis of cohort trends by class background, the only multivariate, cohort-focused analysis that examines how trends in same-sex sexual behavior vary by race is England et al. (2016). They compared the same-sex sexual behavior of whites to blacks, U.S.-born Hispanics, and Hispanic immigrants. Among women, all races showed increases across birth cohorts in sexual experience with same-sex partners, but U.S. born Hispanics' rise was faster than whites for reporting sex with only women, and increases for black women were much steeper than whites for reporting sex with both sexes. For men, the study found no upward trend, and this did not differ by race.

Race and Class Differences and the Role of Structural Constraints. Thus far, we have discussed how same-sex sexual behavior increased because barriers came down, and opportunities and cultural permission increased. However, having sex with same-sex partners could also be encouraged by new structural constraints making heterosexual expression unavailable for some. One dramatic structural change has been the rise in mass incarceration. The total number of persons incarcerated started climbing dramatically in the early 1970s and peaked just after 2000, declining only slightly since then (The Sentencing Project 2017; Travis, Western and Redburn 2014). These trends 
have meant increasing probabilities of incarceration for successive birth cohorts of young American men (Pettit and Western 2004). Prisons are "total institutions" (Goffman 1961) in which inmates are all of the same sex, and from which they cannot leave at will to find sexual or romantic partners. Thus, prisons make heterosexual sex largely inaccessible. ${ }^{4}$ Rules typically prohibit sex between the same-sex inmates as well, whether consensual or coerced (Saum et al. 1995; Tewksbury and Connor 2014). Yet these rules can be hard for officials to enforce as inmates often live in close, overcrowded quarters, and there are regular periods of reduced supervision (Ibrahim 1974; Mahon 1996). Also, some correctional staff are deliberately lax in enforcing sexual behavior bans (Seal et al. 2008; Robertson 2003). Imperfect enforcement thus makes sex with fellow inmates possible, and certain aspects of prison, such as the inaccessibility of heterosexual sex and the sexsegregated environment, might lead some men or women who had not previously done so to have sex with same-sex partners while incarcerated. Since a much higher proportion of men than women are incarcerated, so much so that over $90 \%$ of state and federal prisoners are men (The Sentencing Project 2017), we would expect the increase in incarceration to have a larger effect on men's than women's trend in same-sex behavior. Among men, if incarceration affected sexual behavior, we would also expect effects to be stronger for blacks, since they are incarcerated at levels dramatically above their share of the population (Pettit and Western 2004), and their incarceration trended upward more strongly (National Research Council 2014).

Research on sex between male inmates confirms that it is quite common. There is sexual assault between prisoners, as well as sexual assault by prison staff against inmates (Beck et al. 2013; Struckman et al. 1996; Struckman-Johnson and Struckman-Johnson

\footnotetext{
${ }^{4}$ Moreover, very few prisoners qualify for conjugal visits (Goldstein 2015).
} 
2006). Yet evidence suggests that the preponderance of sexual activity in prison is consensual (Saum et al. 1995). As for how common such sex is, one study by Wooden and Parker (1982) took a random sample of inmates in a California prison and found that, while $78 \%$ of the sample identified as heterosexual, $65 \%$ claimed to have engaged in consensual sex with another man while in prison. The study finding the lowest percent of prisoners reporting sex with fellow inmates, $2 \%$, came from a prison in Delaware; yet nearly $70 \%$ of the same group of respondents reported that consensual sex between men occurred daily in the prison (Saum et al. 1995). Further studies find a range of estimates that vary from $12 \%$ to $25 \%$ who report consensual sex with fellow inmates (Hensley 2001; Nacci and Kane 1983; Tewksbury 1989). Another study suggests that younger inmates are more likely than older inmates to participate in consensual sex while incarcerated (Tewksbury and Connor 2014). In general, while the range of estimates varies widely, numerous studies make it clear that consensual sex between inmates, while prohibited, is not at all rare. Thus, given the large increase in incarceration rates starting in the early 1970s, with disproportionate rates for black men, we might expect to find increased same-sex sex among successive birth cohorts of men, especially black men.

To relate this to past research, as mentioned, the England et. al (2016) study did not find an upward cohort trend in same-sex sex among men, or any race or class differences in cohort trends. However, their data only covers cohorts born after 1965 (1966-1995). It is possible that one needs to go back farther to see trends for men affected by incarceration; our analysis does this.

\section{DATA AND METHODS}


Data. Our goal is to examine trends in same-sex sexual behavior, and to assess whether they differ by race, class background, gender, or intersections of these characteristics. To do so, we use pooled cross-sectional data from the GSS, collected in 1988, 1989, 1990, 1991, 1993, 1994, and then every two years until $2016 .{ }^{5}$ Questions about sexual partners were self-administered, either with a written questionnaire or with a computer, in the case of later waves. Given the prevalence of bias against having samesex sex, the fact that this portion of the questionnaire was not face-to-face makes it more likely that those with same-sex sexual experience were willing to answer truthfully (Villarroel et al. 2006). GSS respondents can be of any age above 17; we used only respondents between 18 and 69.

Dependent Variables: Sexual Behavior. Our first two dependent variables concern sexual partners since age 18 . We constructed two dependent variables from the following two questions: "Now thinking about the time since your 18th birthday (including the past 12 months) how many female partners have you had sex with?" and "Now thinking about the time since your 18th birthday (including the past 12 months) how many male partners have you had sex with?" Using these questions, we classified respondents on the following two dependent variables: 1) has had sex with other- and same-sex partners since age 18 (versus had sex with only other-sex partners, or no one), and 2) has had sex with only same-sex partners since age 18 (versus had sex with only other-sex partners, both sexes, or no one).

A second, parallel analysis focuses on who respondents had sex with in the last year. We form two dependent variables using the question: "Have your sex partners in the last 12 months been...?", where the available answers are "Exclusively male," "Both

5 Although the first GSS was collected in 1972, our variables of interest regarding same-sex partners were not added until 1988 or 1989. 
male and female," and "Exclusively female." We classified respondents as follows: 1)

had sex with other- and same-sex partners in the last year (versus had sex with only

other-sex partners or no one in the last year), and 2) had sex with only same-sex partners

in the last year (versus had sex with only other-sex partners, both sexes, or no one in the last year). ${ }^{6}$

Models. We estimate a series of logistic regressions, in which birth cohort indicators are the primary predictors, and in which several variables (described below) are added as controls. Respondent's birth cohort is represented by indicator variables for the following years that a person was born: 1920-45, 1946-55, 1956-65, 1966-75, 197683, and 1984-98. The first and last cohorts were made to cover more years because, without this, their Ns would be unreliably small. (Even with this, the last cohort is less than half the size of most.)

We do not include period in our main models, but we do employ controls for age with dummy variables entered for every two years of age. If our data were from a single cross-sectional survey, it would be impossible to control for age in models assessing cohort change because cohort would perfectly predict age. Because we cumulate data from 1988-2016 surveys, there is age variation in each cohort. Controlling for age is crucial for assessing cohort change because the birth cohorts in our GSS data differ

\footnotetext{
${ }^{6}$ As two prior studies on trends in same-sex sexual behavior have been conducted using the NSFG (Copen et al. 2016; England et al. 2016), it is interesting to contrast GSS and NSFG surveying procedures.

Screening questions for the NSFG that were used to path men and women into questions about same-sex partners differed by gender; men were asked if they had ever had oral sex with a man, and if they had ever had anal sex with a man, and were only asked how many male sexual partners they had ever had if they answered yes to one of these two questions; otherwise, they were assumed to have had none. In contrast, NSFG female respondents were asked if they had any sexual experience with a woman; if they said yes, they were asked their number of female sexual partners. This was true even if, on a separate question, they did not report ever having had oral sex with a woman. In contrast, GSS asks the same questions of all men and women. Thus, the NSFG arguably imposes a higher bar for men than women to report having ever had a same-sex partner.
} 
dramatically by age. For example, the average age of those born in 1920-45 is 59.6, with average ages of 50.1, 40.8, 32.3, 27.9, and 23.7, respectively, for the cohorts born 194655, 1956-65, 1966-75, 1976-83, and 1984-98 (results not shown). These age differences mean recent cohorts are surveyed at ages where they have had much less time during which they might have had a same-sex partner. Thus, unless everyone who ever has a same-sex partner does so at very a young age, which supplementary analyses suggest is not true, ${ }^{7}$ estimates of the probability that persons in recent cohorts ever have a same-sex partner are biased downward unless we include controls for age.

We exclude the survey year (period) from our main models to avoid the familiar age-period-cohort identification problem. Given that our main models do not contain period, the cohort trends that we estimate may contain a combination of cohort and period effects. In an Online Appendix, however, we present evidence suggesting that the cohort change we identify is, at least in part, a cohort effect.

In the models, we include covariates for race, immigration status, region, and mother's education because these variables may affect sexual behavior or identity, and, compositional change across birth cohorts might confound cohort trends. By using these controls, we intend to identify cohort change that is not explained by compositional changes, but by changing behavior within groups defined by these variables. We also include race and mother's education which allows us to interact these two variables with

\footnotetext{
${ }^{7}$ In results not shown, we have divided cohorts into three broad groups, and, within them, examined the (simple unadjusted) percent of those at various ages who have had sex with both sexes. In the first cohort, born 1920-55, percents don't rise with age. But in cohorts born 1956-75 and 1976-98, both men and women have a nearly monotonically increasing percent who have had sex with both sexes. For men born $1956-75$, it is $2.95 \%$ among those age $18-24$, rising to $5.89 \%$ by age $35-39$, and $10.04 \%$ by age $50-60$. The analogous percents for women are $4.67 \%, 5.90 \%$, and $7.78 \%$. Among men born in 1976-98, the sample contains no one over 40, but the percent who have had sex with both sexes rises from $4.64 \%$ among those 18-24 to $9.41 \%$ among those $35-40$. The analogous percents for women are $8.97 \%$ and $13.68 \%$. (More detailed results available upon request.) The results suggest that some individuals have their first same-sex partner as late as their 30s, 40s, or 50s. This shows the importance of controlling for age.
} 
birth cohort and each other; thus, we can ascertain whether trends for either gender differ significantly by race or class background, and whether race differences in trends vary by class background.

We estimate separate models for men and women in order to examine whether trends differ by gender. For each gender, we estimate four logistic regression models, predicting the following four outcomes: 1) whether, since age 18, the respondent has had both male and female sexual partners, 2) whether, since age 18 , the respondent has had only same-sex sexual partners, 3) whether, in the last year, the respondent has had both male and female sexual partners, and 4) whether, in the last year, the respondent has had only same-sex sexual partners. ${ }^{8}$ For each of these outcomes, the reference category comprises all categories other than the one listed. For each time frame (since age 18 or last year), our choice of two logistic regressions rather than one multinomial logistic regression (MNL) was because of smaller cell sizes in the MNL approach. Fortunately, a sensitivity test that replaced models 1 and 2 above with one multinomial logistic regression, and another replacing outcomes 3 and 4 with one MNL, both yield similar results to our logistic regressions.

Past research shows that many adults who identify as gay or lesbian, and who have had only same-sex partners in the last year, nonetheless at some time in their past had one or more sexual partners of the other sex (Caudillo and England 2015; Brown and England 2016). Given this, results from outcomes 1 and 2 are useful to consider alongside those from outcomes 3 and 4 .

Eq. 1

\footnotetext{
8 Sometimes, for brevity, we will refer to outcomes 1 and 2 as revealing what the respondent has "ever" done.
} 


$$
\begin{aligned}
\operatorname{logit}\left(p_{i}\right) & =\beta_{0}+\beta_{1}\left(\boldsymbol{C O H O R T}_{i}\right)+\beta_{2}\left(\boldsymbol{A G E}_{i}\right)+\beta_{3}\left(\boldsymbol{M O M E D}_{i}\right)+\beta_{4}\left(\boldsymbol{R A C E}_{i}\right) \\
& +\beta_{5}\left(\text { Immigrant }_{i}\right)+\beta_{6}\left(\boldsymbol{R E G I O N}_{i}\right)+\varepsilon_{-} i
\end{aligned}
$$

The main models (for any of the four outcomes) are described by Equation 1, where capital letters indicate that the construct is represented by a series of indicator variables, and $p$ represents the probability of observing each of the outcomes of interest for person i. COHORT is a set of five binary indicators identifying cohorts 1946-55, 1956-65, 1966-75, 1976-83, and 1984-1998 (the reference is 1920-45); $\boldsymbol{A} \boldsymbol{G E}$ is a set of binary indicators identifying each two years of age for ages 18 to 69 (i.e., 18-19, 20-21, etc. where the reference is $18-19) ; \boldsymbol{M O M E D}$ is a set of two binary indicators that indicate whether a respondent's mother has completed a Bachelor's degree or higher, or a high school degree/some college (the reference is less than a high school degree); $\boldsymbol{R} \boldsymbol{A} \boldsymbol{C E}$ represents two dummy variables indicating whether the respondent is Black or has other race (reference is White); Immigrant is a dummy variable that equals 1 if the respondent was born outside of the U.S., and 0 otherwise; and REGION represents a set of binary indicators for regions Midwest, South and West (reference is Northeast). In the GSS, Hispanic origin was recorded for the first time in 2000, so we excluded this variable to be able to use data since 1988. All of our analyses incorporate the survey weight WTSSALL. For each of our four dependent variables, we estimate the model above and compute predicted probabilities from the outcome for each cohort using an average marginal effects approach.

In each of the four models, we also add interactions between cohort indicators and race to assess whether trends differ by race. We do the same for mother's education, to 
assess whether trends differ between those from higher or lower socioeconomic

backgrounds.

\section{RESULTS}

Trends for Women and Men. Table 1 gives descriptive statistics for our sample, by gender.

\section{[TABLE 1 ABOUT HERE.]}

Turning to our multivariate results, Table 2 displays regression results for women. We find monotonic increases across birth cohorts in whether women had sex with both sexes since age 18, had sex with both sexes in the last year, and had only female sex partners in the last year. We find no increase in having had only female sex partners since age 18. Table 3 displays regression results for men. We find monotonic increases for men in having had both male and female sex partners since age 18. Like the results for women, we find no increase in men having had only same-sex partners since age 18 . The other two outcomes (sex with both sexes in the last year and sex with only same-sex partners in the last year) show some significant increases, but the trend is not monotonic.

\section{[TABLES 2 AND 3 ABOUT HERE.]}

Patterns are seen more easily in Table 4, which shows the predicted probabilities for each cohort on each outcome. The predicted probability that a woman reported sex with both men and women since age 18 was only .01 in the first cohort, born 1920-45, moving monotonically up to .19 in the last cohort, born 1984-98 - a huge increase. Men's predicted values saw an increase from .02 to .12 across cohorts, also a large increase, but not as steep as for women. In results not shown, we pool men and women, and interact gender with all variables to assess whether the gender difference in the trend is 
significant. Using logistic regression the difference is not statistically significant; however, when we estimate a parallel linear probability model the difference is significant $(\mathrm{p}<.05) .{ }^{9}$

\section{[TABLE 4 ABOUT HERE.]}

As the regressions in Tables 2 and 3 showed, and Table 4 confirms, there is no trend in having sex with only same-sex partners since age 18 . For both men and women, the predicted probabilities are always low; they round to either .01 or .02 for every cohort. ${ }^{10}$ In interpreting this result, we note past research showing that many individuals who ultimately come to identify as lesbians or gay men had sex at some point with a member of the other sex (Caudillo and England 2015; Brown and England 2016); the heteronormative environment in which most youth come of age makes it likely that even those attracted largely to those of their same sex will face social pressure to have a partner of the other sex. Thus, the lack of trend in having had only same-sex partners tells us little about trends in the proportion who ultimately live a life in which all or many of their relationships are with same-sex partners. ${ }^{11}$

Table 4 also shows predicted probabilities for what sex partners respondents report having in the last year. While the increase for women in the probability of having partners of both sexes in the last year was shown in Table 2 to be statistically significant, we see in Table 4 that the predicted values are very low, with the increase from a very low predicted value that rounds to .00 ascending only to .02 across cohorts. For men there

\footnotetext{
${ }^{9}$ The coefficient for the last cohort is .15 for women and .09 for men.

${ }^{10}$ Only $220(2.0 \%)$ of the 11,231 men and $135(1.0 \%)$ of the 13,925 women had only same-sex sexual partners since age 18 .

${ }^{11}$ We do not analyze cohort changes in identity - sexual orientation-because a question on sexual orientation has only been in the GSS since 2008, thus making many fewer years of data available for orientation than behavior, which the GSS asked about since 1989.
} 
was no change after the second cohort; the predicted probability was .01 for 1946-55 as well as all subsequent cohorts. We speculate that the relatively low proportions from any cohort for either sex who have sex in a given year with both men and women reflects one of the following two things. First, as discussed above, some of the people who report partners of both sexes since 18 will have solidified a pattern of exclusively same-sex partners by the time of the survey, and thus will have had only same-sex partners in the last year. Second, by their 30s, most people "settle down" into monogamous relationships of some duration; this will usually entail only a single partner in any given year, thus precluding partners of both sexes, even for those with a long-term bisexual identity who maintain an openness in principle to partners of either sex.

While we saw above that having had both sexes as partners ever is much more common than having had only same-sex partners ever, the opposite is true for the last year; having had sex only with same-sex partners in the last year is more common, for either men or women, than having sex with both sexes in the last year. Having only samesex partners last year shows an increase in predicted probability for women from .00 to .05 across birth cohorts. For men, the predicted probability is .02 in the first two cohorts, rises to .03 in the next two, declines to .02 , and then rises to .04 in the last cohort. We would call this no clear trend. When we pool men and women into one regression and interact gender with all variables, we find that the trends in having had same-sex partners only last year are significantly different by gender (results not shown).

Do Trends Differ by Race or Class Background? In results not shown, separately for men and women, we interacted all variables in the regressions in Tables 2 and 3 with mother's education in one set of models, and with race in another. We limit 
these interaction models to our first outcome - whether one has had at least one partner of each sex since 18-because the other three outcomes are sufficiently rare that the logistic models with interactions typically would not produce estimates. Our goal was to ascertain whether cohort change in having had sex with both men and women, net of compositional variables, differs by race or class background. For women, the answer was clear; almost all of the coefficients for the interactions between race and cohort indicators, and between mother's education and cohort (for the overall sample and within race groups) were nonsignificant (results not shown). We conclude that, for women, trends are similar for whites and blacks, and for those with more and less educated mothers.

The story for men is very different; race interacts strongly with cohort, such that the last three cohorts (those born in 1966-75, 1976-83, and 1984-98) showed significantly greater increases for black than white men in having had sex ever with both men and women. Men in the "other" race category showed no different pattern than whites.

While our regression results are not shown, Table 5 shows, separately for black and white men, the predicted probabilities by cohort of having had sex with both women and men since age 18. Black men in the first cohort had a predicted probability of only .01 , which rose to .08 by the cohort born in $1956-65$, to .16 for those born in $1966-75$, to .18 in the cohort born in 1976-83, and to .22 for those born in 1984-98. This dramatic rise estimated for black men, from .01 to .22 across cohorts, is much larger than the rise from .02 to .09 estimated for white men, and the significant interaction terms between race and the last three cohorts tell us that these race differences in trends among men are statistically significant. It is notable that the estimated trend for black men, from .01 to 
.22 , is similar to that for all women, which is from .01 to .19. Indeed, white men are the outliers in showing only moderate upward change, estimated from .02 to .09.

\section{[TABLE 5 ABOUT HERE]}

We suggest that the dramatic rise in incarceration might have led to more increase in sex with same-sex partners among groups most disproportionately incarcerated-black men. If this was true, and involved men who saw themselves as heterosexual before incarceration, then we would expect this increase to show up in black men's trends in having ever had sex with each sex, but not in trends on the other measure. This is exactly what we see. Moreover, the cohorts whose contrast with the first cohort are significantly greater for blacks than whites are those born after 1966 (i.e., those born in 1966-75, 1976-83, and 1984-98); these cohorts turned 20 in the 1980s or later when incarceration was at rising and very high levels. Thus the timing of the interaction plausibly suggests incarceration as a factor.

While there was no consistent measure of incarceration for every year the GSS was conducted, there was a question about incarceration that was asked in 2012 only. We use this measure to examine the possible association between incarceration and same-sex sexual behavior for men. Specifically, respondents in 2012 were asked whether they had "ever spent any time in jail or prison," coded as 0 for "no" and 1 for "yes." Using this variable, we conduct a cross-tabulation of prior incarceration and sex with both sexes ever (see Table 6). Results show that among all men who have spent time in prison or jail, $11.27 \%$ also report sex with both sexes, while the percent of all men who report sex with both sexes who have never spent time in jail or prison is much lower $(6.33 \%)$.

[TABLE 6 ABOUT HERE] 
We cannot sensibly include this variable in our main regressions because the $\mathrm{N}$ is drastically reduced to only the 2012 sample, and cohort is more collinear with age when there is only one survey year (it would be completely collinear if both were entered linearly). However, in results not shown, we do include the measure of prior incarceration as a predictor variable in a model that predicts whether men have had sex with both sexes since age 18 on this limited sample. We include broad indicators for cohort and age, and the same the compositional controls as in our main analyses. In doing so, we find a significant and positive relationship between incarceration and sex with both sexes among men in the 2012 sample - specifically, results show that men who had spent time in prison or jail had 3 times the odds of reporting sex with both sexes, compared to men who did not.

Sensitivity Test. To check the robustness of our main findings, we conduct a supplementary analysis that implements a stricter threshold for same-sex sexual behavior than our main models do. Recall that our main models estimate odds ratios for reporting sex with at least 1 same-sex and at least 1 other-sex partner since age 18. In this sensitivity test, we predict odds ratios for reporting sex with at least 2 same-sex partners and at least 1 other-sex partner since age 18 . We do this separately for all women, all men, and black men, and compute predicated probabilities from these logistic regressions using the "margins" command in Stata. Results are displayed in our Online Appendix, and show that even using a more stringent criterion, we find significant cohort change across these groups.

\section{CONCLUSION}


We have shown a steady, monotonic increase across birth cohorts in women's experience with same-sex sex partners - significant increases in the proportion of women who a) have had sex since age 18 with both men and women, b) have done the same in the last year, and c) have had sex with only women in the last year. Men also showed a significant increase in having had sex with both sexes since age 18 , but inconsistent patterns on the other measures. These changes make clear that, although the gender of partners who we have sex with may be strongly influenced by genetic proclivities, sexual behavior is also strongly influenced by social forces (Diamond and Rosky 2016).

Contributions of our analysis include the long range of cohorts-from those born in 1920 to those born in 1998 - that we considered, the four measures of sexual behavior with same-sex partners that we considered, and the fact that our models controlled for compositional change across cohorts in age, immigration status, race, and mother's education (an indicator of class background). One limitation of our analysis is that, while we have interpreted increases in reports of sex with same-sex partners as indicative of real behavior changes, we cannot be certain that the observed change isn't an increase in the willingness to disclose sex with partners of the same-sex rather than a change in actual behavior. We believe, however, that the increases are large enough that they are unlikely to be entirely a function of declines in under-reporting. Another limitation is that, while our analysis shows cohort change, given the familiar age-period-cohort issue, we cannot be sure what mix of cohort and period effects this change represents. A final limitation is that, despite our demonstration of cohort change, we could not test the explanations for the change we have offered - these must be seen as hypotheses needing 
further research. For example, we suggested that sexual behavior may have changed because of liberalizing attitudes, the rise of the internet, increased incarceration, and so forth. But we could not test whether these are the explanations. In some cases this was because the GSS data did not have measures of these factors, and while other data sources provide some information on these hypothesized explanatory factors, they do not allow us to tag them to the birth cohorts that were our independent variables. Despite this limitation, some parts of our analysis did provide hints about causes of cohort change.

First, we were able to control for compositional change in race, immigrant status, age, and mother's education, so we know that the cohort trends we identify are not due to compositional change in these factors. Moreover, our assessments of how trends differ by gender, race, class background, and interactions of these factors provide hints about factors behind change, as we review below.

Recognizing that these are speculations, we start by suggesting that the following factors may be behind the cohort change we identified: Changing attitudes and laws gave increased legitimacy to same-sex relationships; the gay rights movement and the sexual revolution both inspired cohort changes in increased same-sex sexuality; the rise of the internet and the emergence of "gayborhoods" made finding partners easier and more accessible for sexual minorities; a change in the life course where recent cohorts of young adults spend more years out of their parental households before marriage decreased parental influence over mate selection, and made formerly transgressive choices more feasible; and finally, dramatic increases in the proportion of the population incarcerated exposed more men to a massive constraint on their heterosexual expression, which might have led some to have sex with a same-sex partner. 
We turn now to our speculative explanations for the specific group differences in trends that we find. We find that trends in having sex with same-sex partners varied by gender, and involved a gender-race intersection. Among women, the predicted probability of having ever had sex with both men and women moved from .01 in the cohort born 1920-45 to .19 among those born in 1984-98, while the analogous increase for men was .02 to .12- a steeper trend for women than men.

Why were upward trends in same-sex sexual experience stronger and more consistent for women than men? We speculate that the reason for this concerns the asymmetry of the gender revolution. While some feminists urged an acceptance of men doing things seen as feminine, and a revalorization of traditionally feminine activities, the average person received a different message from the gender revolution, which mostly involved women changing by moving into traditionally male positions and styles. Thus, the continued devaluation of the feminine, combined with the fact that same-sex relationships are typically still seen as gender-bending, meant that engaging in them entailed losing status for men more than it did for women. Put simply, contemporary women interested in sexual relationships with same-sex partners feel freer than men to explore them.

To make gender analyses intersectional requires that we ask whether gender differences are themselves different by race or class, or whether race and class differences vary by gender. In exploring these questions, we found that trends among women were not significantly different by race or class backgrounds; women of all races and whose mothers had all levels of education showed similar increases on all three indicators that rose. But among men, the trend differed dramatically (and statistically 
significantly) by race. The predicted probability that a black man reported having had at least one partner of each sex since age 18 rose from .01 to .22 across cohorts, much more than the rise from .02 to .09 for white men. Indeed, the trend for black men, estimated from .01 to .22 , is similar to that estimated for all women, from .01 to .19. White men were the outliers in showing only moderate change, estimated from .02 to .09.

Why was the trend so much more dramatic for black men, such that they had the same trends as both black and white women? Or to put the same question a different way, why didn't the explanation we provided for why men would change less than womenbecause men have less permission to transgress gender norms - apply to blacks? Is it that black men have become unusually liberal in attitudes about gay sex — more liberal than other groups? Evidence from the General Social Survey argues against this; while black men, like other groups, have liberalized in their attitudes, being black or male or having lower education each predict being more likely to believe that homosexuality is wrong (Ford and England 2016). Thus, far from having the most cultural permission for sex with men, the peers of black men, especially those with low education, are probably less tolerant of same-sex sexuality. But recent cohorts of black men have also disproportionately experienced incarceration (Pettit and Western 2004), and the extreme constraint on heterosexual expression that it entails. Thus, we suggest that incarceration trends may explain the stronger upward trend among black than white men in having had both male and female partners since age 18. If this is true, it implies that two broad kinds of changes affected trends, and impacted groups differently. A number of permissiongiving cultural and social changes made it more possible and acceptable to have same-sex partners, but moreso for women than men. Separate from this, black men faced uniquely 
high and increasing levels of incarceration across birth cohorts. This isolated black men from women and severely constrained heterosexual expression, sometimes for years, and this may have prompted some who would not have done so otherwise to have sex with men.

Regardless of the group in question, a deeper understanding of the implications of our findings requires panel data that would tell us more about sexual life cycles. Consider the predicted values for women (.19) and men (.12) in the most recent cohort for having had sex at least once with a member of each gender since age 18 . How often were these same-sex sexual experiences part of each of the following kinds of life cycle progression?: An early same-sex exploration later abandoned for heterosexual relationships; an experience born of a temporary constraint such as incarceration that may or may not affect future choices; a part of the process of "coming out" as gay or lesbian; the behavioral expression of an enduring bisexual identity; part of a pattern of sexual fluidity; or something else? The data at hand give us little information with which we can answer these questions, except to say that only a very small proportion of those who ever have a same-sex partner did so in the last year. ${ }^{12}$ For either respondents' entire life since age 18 , or the last year, Table 4 allows us to add together those who had only same-sex partners and those who had partners of each sex to see the entire proportion who had a same-sex partner. Adding both groups shows that the predicted probabilities for a samesex partner in the last year were only .03 for women, and .05 for men - dramatically

\footnotetext{
12 Our sensitivity test, shown in the Online Appendix, revealed that the upward trend for women in having ever had sex with both men and women was only about half as steep if we used two same-sex partners ever as the threshold instead of one, while requiring two partners reduced the upward trend less for men. Thus, some of the steeper trend among women than men in having ever had at least one male and at least one female partner is accounted for by more women than men having had only one same-sex partner. Unpacking this pattern would also benefit from panel data.
} 
lower than the last-cohort probabilities for having ever had a same-sex partner $(.20$ for women and .14 for men). Of course, most any behavior will have a higher probability across one's adult lifetime than last year. Still, the small proportion of those who have ever had a same-sex partner who did so in the last year suggests that the experiences may be transitory for many. Only panel data asking the same people in multiple years about their sexual behavior and identities could allow us to assess the relative prevalence of the life cycle patterns mentioned above. At this point, no such data exist from a national probability sample, and they are sorely needed for future research. 


\section{References}

Anderson, John E. and R. Stall. 2002. "Increased Reporting of Male-to-Male Sexual Activity in a National Survey." Sexually Transmitted Diseases 29:643-46.

Anderson, Robert and Tina Fetner. 2008. "Cohort Differences in Tolerance of Homosexuality: Attitudinal Change in Canada and the United States, 1981-2000." The Public Opinion Quarterly 72(2): 311-330.

Bailey, Beth. 1997. "Prescribing the Pill: Politics, Culture, and the Sexual Revolution in America's Heartland." Journal of Social History 30(4): 827-856.

Battle, Juan, and Michael Bennett. 2000. "Research on Lesbian and Gay Populations Within the African American Community: What Have We Learned?" African American Research Perspectives 6(2):35-47.

Beck, Allen, Marcus Berzofsky, Rachel Casper, and Christopher Krebs. 2013. "Sexual Victimization in Prisons and Jails Reported by Inmates, 2011-12." Washington: Bureau of Justice Statistics, National Inmate Survey.

Bell, Andrew, and Kelvyn Jones. 2014. "Another 'futile quest'? A simulation study of Yang and Land's hierarchical age-period-cohort model." Demographic Research 30(11): 33360.

Brown, Eliza and Paula England. 2016. "Sexual Orientation Versus Behavior-Different for Men and Women?" Blog post, Contexts website, Sexuality and Inequality Blog. Retrieved December 20, 2016. (https://contexts.org/blog/sexual-orientation-versusbehavior-different-for-men-and-women/)

Butler, Amy. 2005. "Gender Differences in the Prevalence of Same-Sex Sexual Partnering: 1988-2002." Social Forces 84 (1): 421-449.

Caudillo, Mónica L. and Paula England. 2015. "Women's Sexual Orientation and Sexual Behavior: How Well Do They Match?" Blog post, Contexts website, Sexuality and Inequality Blog. Retrieved September 30, 2015. (http://contexts.org/blog/womens-sexualorientation-and-sexual-behavior-how-well-do-they-match/).

Chivers ML, Rieger G, Latty E, Bailey JM. 2004. "A sex difference in the specificity of sexual arousal.” Psychological Science 15:736-44.

Clendinen, Dudley and Adam Nagourney. 2001. Out for good: The struggle to build a gay rights movement in America. Simon and Schuster.

Copen, Casey E., Anjani Chandra, Isaedmarie Febo-Vazquez. 2016. "Sexual Behavior, Sexual Attraction, and Sexual Orientation Among Adults Ages 18-44 in the United States: Data from the 2011-2013 National Survey of Family Growth.” National Health Statistics Reports (88):1-14.

Diamond, Lisa M. 2016. "Sexual Fluidity in Males and Females." Current Sexual Health Reports. DOI 10.1007/s11930-016-0092-z

Diamond, Lisa and Clifford J. Rosky. 2016. "Scrutinizing Immutability: Research on Sexual Orientation and U.S. Legal Advocacy for Sexual Minorities." Journal of Sex Research 53 (4-5):363-391.

Eaklor, Vicki L. and Claude J. Summers. 2009. "Gay Rights Movement, US." Glbtq: the World's Largest Encyclopedia of Gay, Lesbian, Bisexual, Transgender, and Queer Culture. Glbtq, Inc. Retrieved November 2016.

http://www.glbtqarchive.com/ssh/gay_rights_movement_S.pdf 
England, Paula, Emma Mishel, and Mónica L. Caudillo. 2016. "Increases in Sex with SameSex Partners and Bisexual Identity Across Cohorts of Women (but Not Men)." Sociological Science 3:951-970.

Fine, Gary Alan. 1987. With the Boys: Little League Baseball and Preadolescent Culture. Chicago: University of Chicago Press.

Ford, Jessie and Paula England. 2016. "Who Thinks Sex with Same-Sex Partners is 'Wrong'?" Blog post, Contexts website, Sexuality and Inequality Blog. (https://contexts.org/blog/who-thinks-sex-with-same-sex-partners-is-wrong/).

Gallup. 2012. "U.S. Acceptance of Gay/Lesbian Relations Is the New Normal.” Retrieved February 2016. (http://www.gallup.com/poll/154634/acceptance-gay-lesbian-relationsnew-normal.aspx).

Gallup. 2015. "Marriage.” Retrieved February 2016 (http://www.gallup.com/poll/117328/marriage.aspx).

Ghaziani, Amin. 2014. There Goes the Gayborhood? Princeton University Press.

Goffman, Erving. 1961. Asylums: Essays on the Social Situation of Mental Patients and Other Inmates. Anchor Books.

Goldstein, Dana. 2015. "Conjugal Visits: Why they're disappearing, which states still use them, and what really happens during those overnight visits." The Marshall Project. Retrieved July 2017. (https://www.themarshallproject.org/2015/02/11/conjugalvisits\#.L5XUPkM64).

Hensley, Christopher. 2001. "Consensual Homosexual Activity in Male Prisons." Corrections Compendium 26(1): 1-4.

Herek, Gregory M. 2008. "Hate Crimes and Stigma-Related Experiences Among Sexual Minority Adults in the United States: Prevalence Estimates From a National Probability Sample.” Journal of Interpersonal Violence 24(1):54-74.

Human Rights Campaign. 2016. "2016 State Equality Index: A Review of State Legislation Affecting the Lesbian, Gay, Bisexual and Transgender Community and A Look Ahead in 2017." Retrieved July 2017. (http://www.hrc.org/campaigns/state-equality-index).

Ibrahim, Azmy Ishak. 1974. "Deviant sexual behavior in men's prisons." Crime and Delinquency 20(1): 38-44.

Joyner, Kara, and Edward O. Laumann. 2001. "Teenage Sex and the Sexual Revolution.” Pp. 41-71 in Edward O. Laumann and Robert T. Michael (Eds.), Sex, Love, and Health in America. Chicago: University of Chicago Press.

Kozloski, Michael J. 2010. "Homosexual Moral Acceptance and Social Tolerance: Are the Effects of Education Changing?" Journal of Homosexuality 57(10): 1370-1383.

Laumann, Edward O, John H. Gagnon, Robert T. Michael, and Stuart Michaels. 1994. The Social Organization of Sexuality: Sexual Practices in the United States. Chicago: University of Chicago Press.

Levanon, Asaf, Paula England and Paul Allison. "Occupational Feminization and Pay: Assessing Causal Dynamics Using 1950-2000 Census Data.” Social Forces 88(2):865892.

Lewis, Gregory B. 2003. "Black-White Differences in Attitudes toward Homosexuality and Gay Rights" Public Opinion Quarterly 67 (1): 59-78.

Lewis, Gregory B. 2015. "Support for Same-Sex Marriage: Trends and Patterns." Paper presented at the annual meeting of the American Sociological Association, Chicago, Illinois, August 22, 2015. 
Loftus, Jeni. 2001. "American's Liberalization in Attitudes Toward Homosexuality, 19731998." American Sociological Review 66:762-782.

Mahon, Nancy. 1996. "New York inmates' HIV risk behaviors: The implications for prevention policy and programs." American Journal of Public Health 86: 1211-1215.

Mishel, Emma. 2016. "Discrimination against Queer Women in the U.S. Workforce: A Résumé Audit Study." Socius: Sociological Research for a Dynamic World. 2: 1-13.

Mishel, Emma and Mónica Caudillo. 2017. "Google Searches Show More Worry over Gay Men and Boys than over Gay Women and Girls." Contexts: Understanding People in their Social Worlds. (https://contexts.org/blog/google-searches-show-more-worry-overgay-men-and-boys-than-over-gay-women-and-girls/).

Nacci, Peter L. and Thomas R. Kane. 1983. "The Incidence of Sex and Sexual Aggression in Federal Prisons." Federal Probation 47(4):31-36.

National Research Council. 2014. The Growth of Incarceration in the United States: Exploring Causes and Consequences. Committee on Causes and Consequences of High Rates of Incarceration, J. Travis, B. Western, and S. Redburn, Editors. Committee on Law and Justice, Division of Behavioral and Social Sciences and Education. Washington, DC: The National Academies Press.

O’Brien, Jodi. 2001. "Heterosexism and Homophobia." Pp. 6672-76 in International Encyclopedia of the Social \& Behavioral Sciences, edited by N. Smelser and P. Baltes. Oxford, UK: Elsevier.

Obergefell v. Hodges, $135 \underline{\text { S. }}$ Ct. 2071 - 2015.

Ohlander, Julianne, Jeanne Batalova, and Judith Treas. 2005. "Explaining Educational Differences on Attitudes Toward Homosexual Relations. " Social Science Research 34(4): 781-799.

Pascoe, C.J. 2007. Dude You're a Fag: Masculinity and Sexuality in High School. Los Angeles, CA: University of California Press.

Pettit, Becky and Bruce Western. 2004. "Mass Imprisonment and the Life Course: Race and Class Inequality in U.S. Incarceration.” American Sociological Review 69: 151-69.

Pew Research Center. 2015. "Changing Attitudes on Gay Marriage." Retrieved February 2016 (http://www.pewforum.org/2015/07/29/graphics-slideshow-changing-attitudes-on-gaymarriage).

Robertson, James E. 2003. "Rape among incarcerated men: Sex, coercion and STDs.” AIDS Patient Care and STDs 17: 423-430.

Robinson, Ira, Ken Ziss, Bill Ganza, and Stuart Katz. 1991. "Twenty Years of the Sexual Revolution, 1965-1985: An Update." Journal of Marriage and the Family 53(1): 216-20.

Rosenfeld, Michael J. 2007. The Age of Independence: Interracial Unions, Same-Sex Unions and the Changing American Family. Harvard University Press.

Rosenfeld, Michael J. and Reuben J. Thomas. 2012. "Searching for a Mate: The Rise of the Internet as a Social Intermediary." American Sociological Review 77(4): 523-547.

Saum, Christine A., Hilary L. Surratt, James A. Inciardi, and Rachael E. Bennett. 1995. "Sex in Prison: Exploring the Myths and Realities." The Prison Journal 75(4):413-430.

Seal, David Wyatt, Andrew D. Margolis, Kathleen M. Morrow, Lisa Belcher, James Sosman, John Askew, and the Project START Study Group. 2008. "Substance use and sexual behavior during incarceration among 18- to 29-year-old men: Prevalence and Correlates." AIDS Behavior 12: 27-40. 
Silva, Tony. 2016. "Bud-Sex: Constructing Normative Masculinity among Rural Straight Men That Have Sex With Men.” Gender \& Society 31(1): 1-23. https://doi.org/10.1177/0891243216679934

Smith, Daniel Scott. 1973. "The Dating of the American Sexual Revolution: Evidence and Interpretation." Pp. 321-335 in Michael Gordon (Ed.), The American Family in SocialHistorical Perspective. New York: St. Martin's Press.

Smith, Tom W. 2011. "Public Attitudes towards Homosexuality." NORC, University of Chicago. Retrieved February 2016 (http://www.norc.org/PDFs/2011\%20GSS\%20Reports/GSS_Public\%20Attitudes\%20To ward\%20Homosexuality_Sept2011.pdf).

Struckman-Johnson, Cindy, David Struckman-Johnson, Lila Rucker, Kurt Bumby, and Stephen Donaldson. 1996. "Sexual Coercion Reported by Men and Women in Prison." Journal of Sex Research 33(1): 67-76

Struckman-Johnson, Cindy and David Struckman-Johnson. 2006. "A Comparison of Sexual Coercion Experiences Reported by Men and Women in Prison." Journal of Interpersonal Violence 21(12): 1591-1615.

Tewksbury, Richard. 1989. "Measures of sexual behavior in an Ohio prison." Sociology and Social Research 74(1): 34-39.

Tewksbury, Richard and David Patrick Connor. 2014. "Who is Having Sex Inside Prison?" Deviant Behavior 35: 993-1005.

The Sentencing Project: Research and Advocacy for Reform. June 2017. "Trends in U.S. Corrections." Retrieved July 2017. (http://sentencingproject.org/wpcontent/uploads/2016/01/Trends-in-US-Corrections.pdf).

Tilcsik, András. 2011. "Pride and Prejudice: Employment Discrimination against Openly Gay Men in the United States." American Journal of Sociology 117(2): 586-626.

Travis, Jeremy, Bruce Western, and Steve Redburn. 2014. The Growth in Incarceration Rates in the United States: Exploring Causes and Consequences. Washington DC: The National Academies Press.

Turner, Charles F., Maria A. Villarroel, James R. Chromy, Elizabeth Eggleston and Susan M. Rogers. 2005. "Trends: Same-Gender Sex among U.S. Adults: Trends across the Twentieth Century and during the 1990s." The Public Opinion Quarterly 69(3): 439-462.

Twenge, Jean M., Ryne A. Sherman, and Brooke E. Wells. 2016. "Changes in American Adults' Reported Same-Sex Sexual Experiences and Attitudes, 1973-2014.” Archives of Sexual Behavior DOI 10.1007/S10508-01-0769-4.

Villarroel, Maria A. et al. 2006. "Same-Gender Sex in the United States Impact of T-Acasi on Prevalence Estimates." Public Opinion Quarterly 70(2):166-96.

Ward, Jane. 2015. Not Gay: Sex Between Straight White Men. New York, NY: NYU Press.

Watts, Alexander W. 2015. "Sexuality, Gender, and Morality: Testing an Integrated Theory of Anti-Gay Prejudice." Unpublished paper. Stanford, CA: Stanford University.

Wooden, Wayne and Jay Parker. 1982. Men behind bars: Sexual exploitation in prison. New York: Plenum.

Wu, Lawrence W., Steven Martin, and Paula England. 2017. "The Decoupling of Sex and Marriage: Cohort Trends in Who Did and Did Not Delay Sex Until Marriage for U.S. Women Born 1938-1985." Sociological Science 4: 151-175.

Yang, Y. and Keneth C. Land. 2013. Age-period-cohort analysis: New models, methods, and empirical applications. CRC Press. 


\section{Tables}

Table 1. Means on all Variables, by Gender

\begin{tabular}{lrc}
\hline Sex Since Age 18 & Women & Men \\
$\quad$ With Both Sexes & 0.06 & 0.05 \\
$\quad$ With Same-Sex Only & 0.01 & 0.02 \\
Sex in Last Year & & \\
$\quad$ With Both Sexes & 0.01 & 0.01 \\
$\quad$ With Same-Sex Only & 0.02 & 0.03 \\
Birth Cohort & & \\
1920-45 & 0.18 & 0.17 \\
1946-55 & 0.21 & 0.22 \\
1956-65 & 0.25 & 0.25 \\
1966-75 & 0.20 & 0.19 \\
1976-83 & 0.10 & 0.10 \\
1984-98 & 0.06 & 0.06 \\
Race & & \\
$\quad$ White & 0.77 & 0.81 \\
$\quad$ Black & 0.16 & 0.12 \\
$\quad$ Other Race & 0.07 & 0.07 \\
Mother's Education & & \\
$\quad$ < HS & 0.32 & 0.27 \\
$\quad$ HS/Some College & 0.55 & 0.58 \\
$\quad$ BA+ & 0.13 & 0.15 \\
Region & & \\
$\quad$ Northeast & 0.19 & 0.18 \\
$\quad$ Midwest & 0.24 & 0.25 \\
South & 0.36 & 0.35 \\
$\quad$ West & 0.21 & 0.22 \\
Agmigrant & & 0.10 \\
N of respondent & 13040 \\
\hline
\end{tabular}


Table 2. Odds ratios from four logistic regressions predicting whether women (1) had male and female sexual partners since age 18, (2) had only female sexual partners since age 18, (3) had male and female sexual partners in the last year, and (4) had only female sexual partners in the last year.

\begin{tabular}{|c|c|c|c|c|}
\hline \multicolumn{5}{|l|}{ Birth Cohort } \\
\hline \multicolumn{5}{|l|}{$\begin{array}{l}\text { Birth Cohort } \\
\text { 1920-45 (reference) }\end{array}$} \\
\hline $1946-55$ & $2.84 * * *$ & $1.98^{\wedge}$ & 1.47 & $3.93 * * *$ \\
\hline $1956-65$ & $3.71 * * *$ & 1.19 & $2.86^{\wedge}$ & $2.89 * *$ \\
\hline $1966-75$ & $6.08^{* * *}$ & 1.60 & $3.74^{\wedge}$ & $5.10 * * *$ \\
\hline $1976-83$ & $10.60 * * *$ & 0.91 & $8.01 * *$ & $5.51 * * *$ \\
\hline 1984-98 & $17.26 * * *$ & 1.88 & $11.48 * * *$ & $9.80 * * *$ \\
\hline \multicolumn{5}{|l|}{ Mother's Education } \\
\hline \multicolumn{5}{|l|}{$<$ HS (reference) } \\
\hline HS/Some College & 0.97 & $3.67 * * *$ & 1.20 & $1.54^{*}$ \\
\hline $\mathrm{BA}+$ & 1.09 & $2.64 *$ & $1.91^{\wedge}$ & 1.31 \\
\hline \multicolumn{5}{|l|}{ Race } \\
\hline \multicolumn{5}{|l|}{ White (reference) } \\
\hline Black & 1.06 & 0.66 & 1.43 & 0.94 \\
\hline Other Race & $0.70^{\wedge}$ & 1.31 & 0.72 & 0.87 \\
\hline Immigrant & 1.18 & 1.18 & 0.92 & 0.87 \\
\hline \multicolumn{5}{|l|}{ Region } \\
\hline \multicolumn{5}{|l|}{ Northeast (reference) } \\
\hline Midwest & 0.92 & 0.68 & $0.48^{\wedge}$ & $0.66^{*}$ \\
\hline South & 1.04 & 0.81 & 0.80 & 0.85 \\
\hline West & $1.53 * *$ & 0.84 & 1.61 & 0.91 \\
\hline Intercept & $0.00 * * *$ & $0.00 * * *$ & $0.00 * * *$ & $0.00 * * *$ \\
\hline $\mathrm{N}$ & 12810 & 12371 & 12246 & 14529 \\
\hline
\end{tabular}

Note: 2-year indicator variables for ages 18-69 also included in all models, but Odds Ratios not shown. 
Table 3. Odds ratios from four logistic regressions predicting whether men (1) had male and female sexual partners since age 18, (2) had only male sexual partners since age 18, (3) had male and female sexual partners in the last year, and (4) had only male sexual partners in the last year.

Birth Cohort

1920-45 (reference)

1946-55

1956-65

1966-75

1976-83

1984-98

$\begin{array}{llll}2.23 * * * & 0.94 & 3.33^{*} & 1.18 \\ 3.33^{* * *} & 1.63 & 4.81^{*} & 2.11^{* *} \\ 5.66 * * * & 1.48 & 5.34^{*} & 1.89^{*} \\ 7.17 * * * & 0.91 & 4.38^{\wedge} & 1.53 \\ 8.60^{* * *} & 1.81 & 5.60^{\wedge} & 2.39^{*}\end{array}$

Mother's Education

$<$ HS (reference)

HS/Some College

$\begin{array}{llll}0.86 & 0.95 & 0.86 & 0.87\end{array}$

$\mathrm{BA}+$

$0.68 * \quad 1.22$

$1.50 \quad 0.87$

Race

White (reference)

Black

Other Race

$\begin{array}{lll}1.65^{* * *} & 1.53^{\wedge} \quad 1.62\end{array}$

1.24

$1.44^{\wedge}$

0.94

1.13

1.04

Immigrant

1.05

0.79

1.91

0.76

Region

Northeast (reference)

Midwest

$1.32^{\wedge} \quad 0.85$

1.52

0.87

South

1.08

0.73

0.83

0.89

West

1.09

0.77

0.88

0.95

Intercept

$0.00 * * *$

$0.03 * * *$

$0.00 * * *$

$0.02 * * *$

$\mathrm{N}$ $10293 \quad 10293$ 10478

11742

$* * * \mathrm{p}<0.001 ; * * \mathrm{p}<0.01 ; * \mathrm{p}<0.05 ;{ }^{\wedge} \mathrm{p}<0.10$

Note: 2-year indicator variables for ages 18-69 also included in all models, but Odds Ratios not shown. 


\begin{tabular}{|c|c|c|c|c|c|c|c|c|}
\hline \multirow[b]{2}{*}{ Cohort } & \multicolumn{2}{|c|}{ SS+OS since 18} & \multicolumn{2}{|c|}{ SS Only since 18} & \multicolumn{2}{|c|}{ SS+OS Last Year } & \multicolumn{2}{|c|}{ SS Only Last Year } \\
\hline & Women & Men & Women & Men & Women & Men & Women & Men \\
\hline $1920-45$ & 0.01 & 0.02 & 0.01 & 0.01 & 0.00 & 0.00 & 0.00 & 0.02 \\
\hline $1946-55$ & 0.04 & 0.04 & 0.01 & 0.01 & 0.00 & 0.01 & 0.02 & 0.02 \\
\hline $1956-65$ & 0.05 & 0.05 & 0.01 & 0.02 & 0.01 & 0.01 & 0.01 & 0.03 \\
\hline $1966-75$ & 0.08 & 0.08 & 0.01 & 0.02 & 0.01 & 0.01 & 0.02 & 0.03 \\
\hline 1976-83 & 0.12 & 0.10 & 0.01 & 0.01 & 0.01 & 0.01 & 0.03 & 0.02 \\
\hline $1984-98$ & 0.19 & 0.12 & 0.01 & 0.02 & 0.02 & 0.01 & 0.05 & 0.04 \\
\hline
\end{tabular}

Note: Probabilities are from regression results in Tables 2-3, using average marginal effects. "SS+OS" = had same-sex and other-sex partners. "SS Only"= had only same-sex partners.

\begin{tabular}{|l|l|l|}
\hline \multicolumn{3}{|l|}{ Table 5. Predicted Probabilities of Reporting Sex with Both } \\
Men and Women Since Age 18 Among Black and White Men \\
\hline Cohort & Black Men & White Men \\
\hline $1920-45$ & $\begin{array}{l}\mathbf{0 . 0 1} \\
(0.00,0.02)\end{array}$ & $\begin{array}{l}\mathbf{0 . 0 2} \\
(0.01,0.03)\end{array}$ \\
\hline $1946-55$ & $\begin{array}{l}\mathbf{0 . 0 4} \\
(0.02,0.06)\end{array}$ & $\begin{array}{l}\mathbf{0 . 0 3} \\
(0.03,0.04)\end{array}$ \\
\hline $1956-65$ & $\begin{array}{l}\mathbf{0 . 0 8} \\
(0.04,0.12)\end{array}$ & $\begin{array}{l}\mathbf{0 . 0 5} \\
(0.04,0.06)\end{array}$ \\
\hline $1966-75$ & $\begin{array}{l}\mathbf{0 . 1 6} \\
(0.09,0.22)\end{array}$ & $\begin{array}{l}\mathbf{0 . 0 7} \\
(0.05,0.09)\end{array}$ \\
\hline $1976-83$ & $\begin{array}{l}\mathbf{0 . 1 8} \\
(0.07,0.29)\end{array}$ & $\begin{array}{l}\mathbf{0 . 0 7} \\
(0.04,0.11)\end{array}$ \\
\hline $1984-98$ & $\begin{array}{l}\mathbf{0 . 2 2} \\
(0.07,0.37)\end{array}$ & $\begin{array}{l}\mathbf{0 . 0 9} \\
(0.04,0.14)\end{array}$ \\
\hline
\end{tabular}

Note: Probabilities are from separate regressions (not shown) for black and white men, using average marginal effects. $95 \%$ confidence intervals in parentheses. 
Table 6. Percent of Men Who Reported Having Sex With Both Men and Women, By Whether They Have Ever Been in Prison or Jail

\begin{tabular}{|l|l|l|l|}
\hline $\begin{array}{l}\text { Been in Prison or Jail } \\
\text { Ever }\end{array}$ & $\begin{array}{l}\text { Did Not Have Sex With } \\
\text { Both Men and Women }\end{array}$ & $\begin{array}{l}\text { Had Sex With Both Men } \\
\text { and Women }\end{array}$ & Total \\
\hline No & $93.67 \%(414)$ & $6.33 \%(28)$ & $100 \%(442)$ \\
\hline Yes & $88.73 \%(126)$ & $11.27 \%(16)$ & $100 \%(142)$ \\
\hline Total & $92.57 \%(540)$ & $7.53 \%(44)$ & $100 \%(584)$ \\
\hline
\end{tabular}




\section{Online Appendix \\ Increases in Sex with Same-Sex Partners Across U.S. Cohorts Born 1920-1998: A Race-Gender Intersection}

\section{Supplementary Analysis to Assess Whether Cohort Change is Indicative of}

Cohort Effects. In the paper, we have shown cohort change on some measures, but made no claims about whether this cohort change is a cohort or period effect, or some of each. As is well known, there is no sure-fire way to separate age, period, and cohort effects. However, here we present evidence that at least some of the cohort change we identified is a cohort effect. We think it is important to provide this evidence, because a recent analysis by Twenge et al. (2016) argued that the increase in having had sex with a samesex partner identified in their GSS analysis is exclusively due to a period effect, with no cohort effect.

To reach this conclusion, Twenge et al. (2016) estimated a hierarchical AgePeriod-Cohort (APC) model proposed by Yang and Land (2013). By using a mixed model, this strategy intends to avoid the identification problem that arises when age, period, and cohort are included as simultaneous controls in a regression. The identification problem arises because if you know any two of a respondent's age, the survey year, and the year of birth, the third is completely determined by the other two. The Yang-Land model is designed for pooled data from a number of cross-sections, and at the first level it includes linear and quadratic age indicators as covariates, while period and cohort are included as random effects at the second level. Estimated coefficients are only unbiased if one can make the strong assumption that both cohort and period are uncorrelated with any of the covariates (Bell and Jones 2014a; Yang, Yang and Land 2008). If this assumption is violated and, for example, period is correlated with age, the 
model may attribute some of any existing period effect to age. An analogous problem can occur if cohort is correlated with age. However, when using pooled cross-sections from the GSS, the danger of falsely concluding there is an effect of period from a model containing age and period is much greater than the danger of falsely concluding there is an effect of cohort from a model containing age and cohort, because age and period are barely correlated, while age and cohort are necessarily correlated.

Because we include those from 18 to 69 years of age from every survey in our analysis, the correlation between age and period is only 0.09 , with any correlation owing to the glacial change in the age structure; by contrast, for any given group of survey years, GSS does not observe all cohorts at all ages, so in our sample age and cohort are strongly correlated (-0.85). ${ }^{13}$ Given this violation of the assumption of independence between cohort residuals and age covariates, the model that Twenge et al. (2016) estimated, like other APC models that treat cohort and period as random effects, is unlikely to be able to disentangle cohort, period, and age (Glenn 2005; Bell and Jones 2014a). As an example, Reither, Hauser, and Yang (2009) used a hierarchical model to analyze changes in obesity in the US, concluding that changes were mostly due to period effects. However, in a comment on Reither et al. (2009), Bell and Jones (2014b) used simulated data to show that in the presence of a cohort trend and zero period change, Yang and Land's approach incorrectly attributes most of the change to period. Similarly, we believe that the model used by Twenge et al. (2016) was a priori biased to underestimate any existing cohort effect on same sex sexuality. That is, because age is privileged in the model (period and cohort enter only as random effects), and age and

\footnotetext{
${ }^{13}$ For example, in the data we used spanning surveys 1988-2016, those born in 1956-65 included respondents between 24 to 60, while those born in 1984-98 include persons between 18 and 32 . The more recent the cohort, the younger the group of respondents we have data on.
} 
cohort are strongly correlated, much of the cohort effect may have been called an effect of age, and thus any effect of cohort was probably underestimated.

Despite the fact that there is no foolproof way to disentangle cohort and period effects, here we describe several analyses supplementary to our main analyses that suggest that at least some of the cohort change we identify is a cohort effect. We describe results from models that enter age and cohort in models as covariates (sometimes called fixed effects), and period as a random effect. We also present a graphical depiction of the predicted probabilities of having had sex with both men and women from a model like our main model described above, except replacing cohort by period. After obtaining probabilities for each age, we smoothed these predicted probabilities using locally weighted regressions (LOWESS). ${ }^{14}$

The main piece of evidence is Figure A-1, which shows predicted probabilities that women in each period had sex with both men and women since age 18, by age. These probabilities are from a model just like the model in Table 2 predicting women's probability of reporting sex with at least one man and at least one woman since age 18 , except that period was entered instead of cohort, and the predicted probabilities for individual ages for each survey date (period) are smoothed using LOWESS, as described above.

\footnotetext{
${ }^{14}$ For any particular age, this is accomplished by running a regression explaining the probability of interest (as obtained from the model described above) and controlling for age, but restricting the model to a few ages near the age of interest. The model assigns greater weight to the data points corresponding to the central age, and other ages are weighted down as they get away from the center. This regression is repeated to calculate the smoothed predicted probability of interest for each age.
} 


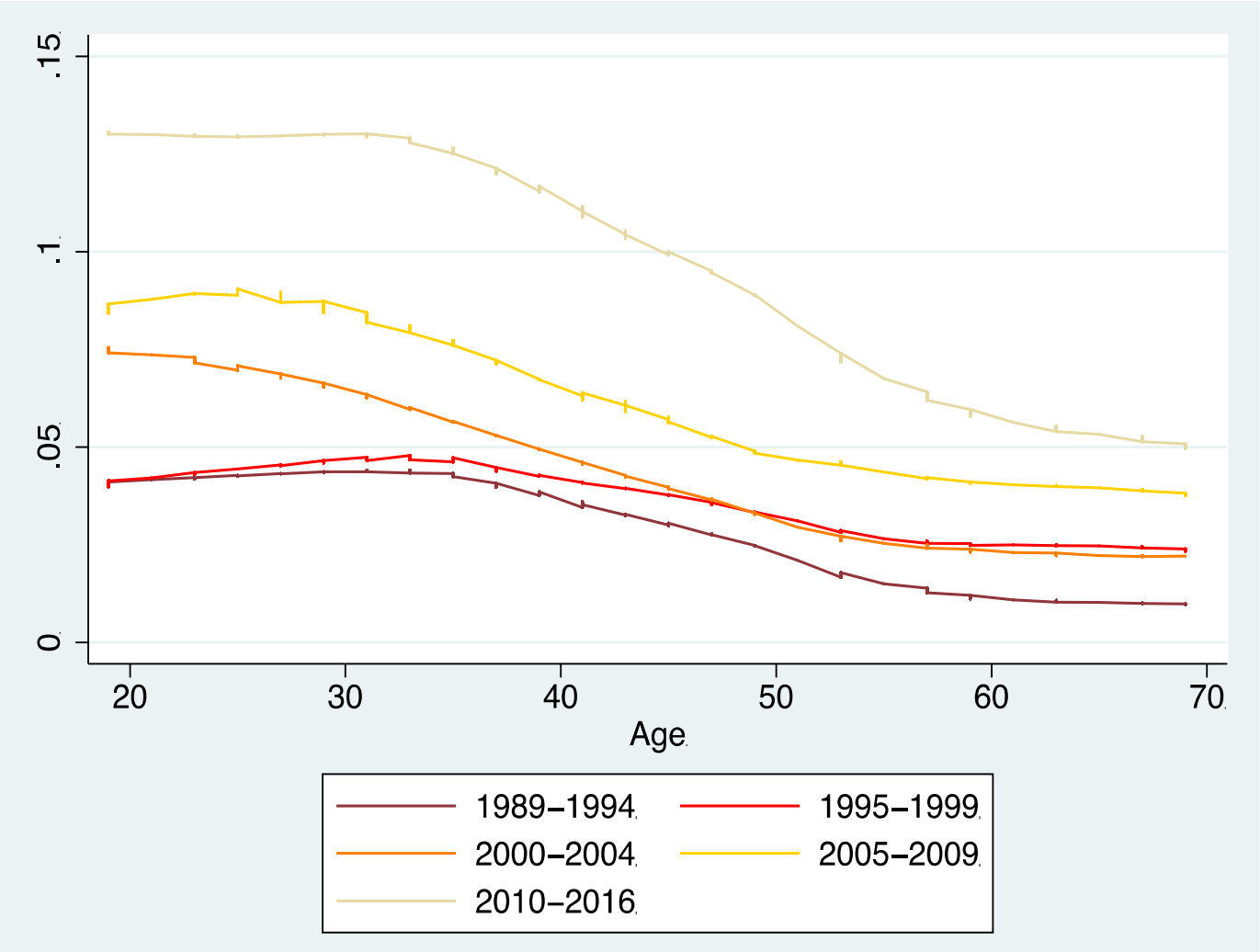

Figure A-1. Predicted Probability that Women Have Had Sex with Both Men and Women Since Age 18, by Age and Period of Survey

Note: From OLS linear probability models containing binary variables for each age and controls for race, mother's education, region, and immigrant status. A separate model was estimated for each period (five intervals of survey dates). Lowess smoothing was performed (see Appendix text).

As the figure shows, the probabilities for each period descend by age in most of the range from age 30 to 60 . For men, the pattern is less clear, but men also show a descent in probabilities with age in some periods (results not shown). This finding is puzzling because it pertains to data from a question about what one has ever done since age 18. If, in addition to having sex with other-sex partners in one's 20 s, one had sex at age 25 with a same-sex partner, then the appropriate answer to the question of whether one has had any same-sex partners is yes, whether one is 30,40 , or 60 years old; there is nothing about aging that would turn a yes into a no, as long as reporting is accurate. Thus, 
in this model that omits cohort indicators, because we find age differences that we know cannot be effects of age, the logical conclusion, given the strong correlation between cohort and age in the data, is that they are a cohort effect. (By contrast, if we examined an analogous graph of predicted probabilities for having had sex last year with both sexes, a downward age curve would be perfectly plausible, and would not be indicative of a cohort effect.) Thus, we take Figure A-1 as indirect evidence of a cohort effect on having ever had sex with both sexes.

We also undertake some additional supplementary analyses to find evidence of cohort effects. Because our models do not enter cohort and age linearly, but rather categorically, our models are identified if we add period indicators to the models in Tables 2 and 3 in the paper. When we estimate these models, which are extremely conservative tests for cohort effects, entering period indicators for each survey year, none of the cohort coefficients remain significant, whether the models are logistic regressions as in Table 2 and 3, or OLS linear probability models. These models are identified but have extreme collinearity. When we collapse categories to make less detailed indicators of age, period, and cohort, some specifications retain significance for cohort effects predicting sex with both same- and other-sex partners for women, while others don't (results not shown).

In another supplementary analysis that is less conservative toward finding cohort effects, we estimate parameters for a linear hierarchical model that, instead of including age, cohort, and period as covariates, includes age and cohort as covariates but period as a random effect. We choose this model to avoid attributing any potential cohort trends to age, which, due to the high correlation between cohort and age, would occur if we 
entered both period and cohort as random effects, and age as a covariate. This analysis is less conservative than including all age, period, and cohort indicators as covariates because it assumes no correlation between period and either age or cohort, although we know that period and cohort, as well as age and cohort, are correlated in these data. When we estimate these models for women, each subsequent cohort sees significantly higher probabilities of having had sex with both sexes since age 18 than the first cohort, with coefficients monotonically larger for each, as was true in our main models. (We get the same result if we estimate a logistic mixed model; however we cannot do this on our other outcomes or for men, because the events are rare enough that the models won't converge.) We find weaker evidence of a monotonically increasing probability for men; coefficients increase across cohorts but then turn down in the last cohort, which is not significantly different from the first. The gender difference in the coefficient for the most recent cohort, 1984-98, is significant $(\mathrm{p}<.05)$ in these models, which mirrors our results in Table 2 (there the gender difference is nonsignificant in the logistic regression but significant in an analogous linear probability model), and supports the notion of a stronger upward trend for women compared to men in sex with both same- and other-sex partners. We repeated this exercise to explain the probability of having had sex with both men and women during the last year. For women, we find a monotonically increasing cohort trend, as we do in our main models, with significant cohort coefficients for cohorts 1976-83 and 1984-98. We find neither significant cohort coefficients nor a clear upward trend for men in this model. Regarding gender differences in cohort coefficients, we find that it is significant $(\mathrm{p}<.05)$ level for the most recent cohort (1984-98). Mirroring results from Table 3, our hierarchical models show a significant cohort increase for women in 
having only women partners in the last year, although increases are only monotonic for women born after 1956. We did not find such a trend for men in this analysis. Regarding the probabilities of having had sex with only same sex partners ever and during the last year, we find no evidence of clear, significant trends for either women or men in these hierarchical models.

In sum, we can be sure that there have been cohort changes in the probability of women and men having had sex with both sexes since 18 , and of women having had same-sex partners only or partners of both sexes in the last year. We make no claims that all of the cohort change is a cohort effect, but we believe that the preponderance of evidence above suggests that at least some of the increase in the proportion of women and men who have had both sexes as partners, ever or recently, is a cohort effect.

2. Sensitivity Tests for Main Findings. To check the robustness of our main findings, we conduct a supplementary analysis that implements a stricter threshold for same-sex sexual behavior than our main models do. Recall that our main models estimate odds ratios for reporting sex with at least 1 same-sex and at least 1 other-sex partner since age 18. In this robustness check, we predict odds ratios for reporting sex with at least 2 same-sex partners and at least 1 other-sex partner since age 18 . We do this separately for all women, all men, and black men, and compute predicated probabilities from these logistic regressions using the "margins" command in Stata. Results are displayed in Table A-1. 
Table A-1. Odds Ratios From Models Predicting Sex with Both Sexes Since Age 18, for All Women, All Men, and Black Men: Comparing Main Paper Results to Those Requiring 2 (Instead of 1) Same-Sex Partners Since Age 18

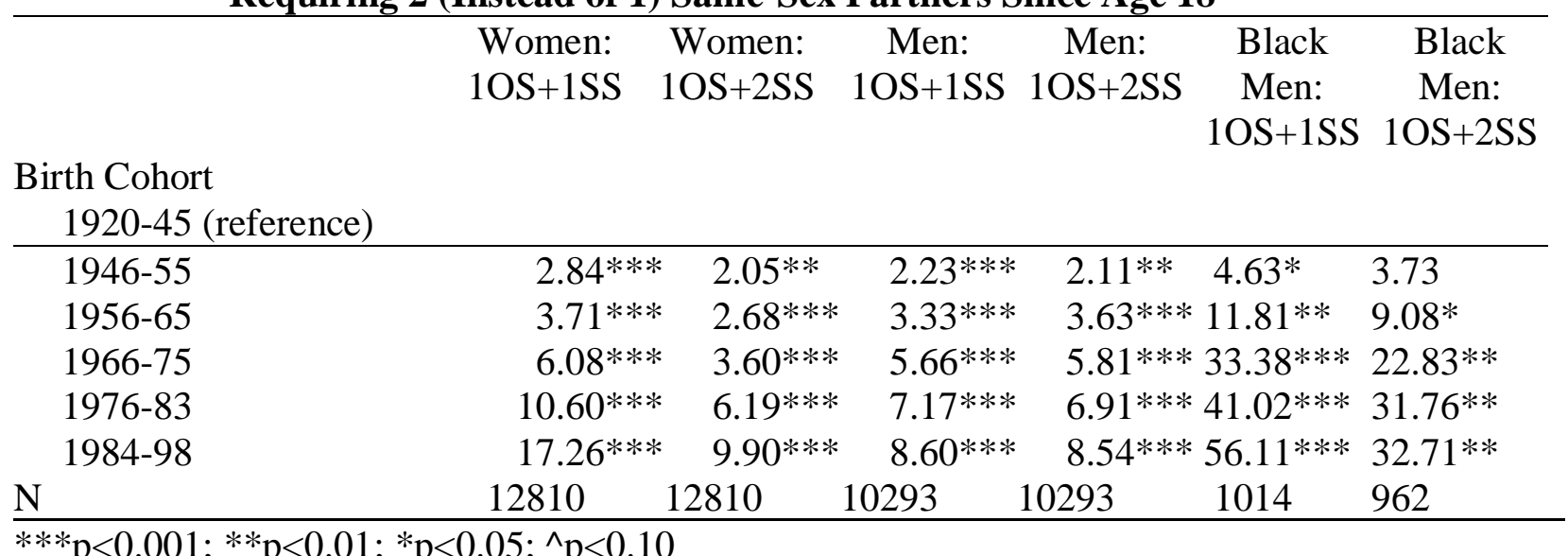

$* * * \mathrm{p}<0.001 ; * * \mathrm{p}<0.01 ;{ }^{*} \mathrm{p}<0.05 ; \wedge \mathrm{p}<0.10$

Note: 2 -yr Indicator variables for ages 18-69, as well as controls for Mother's Education, Race, Immigrant Status, and Region also included in all models, but Odds Ratios not shown. $1 \mathrm{OS}+1 \mathrm{SS}=$ at least one other-sex and at least one same-sex partner since age 18. 1OS+2SS=at least one other-sex and at least two same-sex partners since age 18.

Results in Table A-1 show that, for women, cohort change is evident whether we require at least 1 or 2 same-sex partners, but is much steeper if only 1 is required. By contrast, for all men, the odds ratios showing cohort change are almost identical whether we require that they have had at least 1 or at least 2 same-sex partners, whereas for Black men, like women, change is much steeper if we only require 1 same-sex partner. This seems to imply that, among those who have had at least one partner of each sex, a higher proportion of women and black men than white men have had only one same-sex partner. This can be seen more clearly in the predicted probabilities in Table A-2. 
Table A-2. Predicted Probabilities of Reporting Sex with Both Sexes Since Age 18, for All Women, All Men, and Black Men: Comparing Main Paper Results to Those Requiring 2 (Instead of 1) Same-Sex Partners Sex Since Age 18

\begin{tabular}{|l|l|l|l|l|l|l|}
\hline Cohort & Women: & Women: & Men: & Men: & $\begin{array}{l}\text { Black } \\
\text { Men: } \\
\text { 1OS+1SS }\end{array}$ & $\begin{array}{l}\text { Black } \\
\text { Men: } \\
\text { 1OS+2SS }\end{array}$ \\
\hline $1920-45$ & 0.01 & 0.01 & 0.02 & 0.01 & 0.01 & 0.01 \\
\hline $1946-55$ & 0.04 & 0.02 & 0.04 & 0.02 & 0.04 & 0.03 \\
\hline $1956-65$ & 0.05 & 0.03 & 0.05 & 0.04 & 0.08 & 0.06 \\
\hline $1966-75$ & 0.08 & 0.04 & 0.08 & 0.06 & 0.16 & 0.13 \\
\hline $1976-83$ & 0.12 & 0.06 & 0.10 & 0.07 & 0.18 & 0.16 \\
\hline $1984-98$ & 0.19 & 0.09 & 0.12 & 0.09 & 0.22 & 0.16 \\
\hline
\end{tabular}

Note: Probabilities are from regression results above, using average marginal effects. $1 \mathrm{OS}+1 \mathrm{SS}=$ at least one other-sex and at least one same-sex partner since age 18. 1OS+2SS $=$ at least one other-sex and at least two same-sex partners since age 18.

Table A-2 shows the predicted probabilities from our original models in the paper and the supplemental models that required 2 same-sex partners. For all men, the modelgenerated predicted probabilities of having had partners of both sexes went from .02 to .12 in the paper, which required only one same-sex partner, whereas when the model requires 2 , the probability goes from .01 to .09 . For women, and black men, the differences are more dramatically different when two are required. Whereas the paper showed women's increasing from .01 to .19 , the increase when two same-sex partners are required is from .01 to .09 - exactly the same as the predicted probabilities in the first and last cohort for all men when two are required. Thus, the excess trend for women relative to men appears to come from additional women across cohorts who have had only one female partner. Black men, like women, show a steeper cohort pattern of change, estimated from .01 to .22 in the analysis with 1 same-sex partner as the threshold, but from .01 to .16 when two is the threshold; however, the majority of the cohort trend is there whether 1 or 2 is the threshold.

The findings from this sensitivity test makes us more confident that there is an 
upward trend across cohorts for all groups. However, the fact that the predicted

probability that a woman has had both sexes as partners increases only approximately

half as much with the threshold as two same-sex partners tells us that a significant part of

the rise for women was among women who had only one partner. Men's probability also

fails to rise as much with a threshold of two, but the predicted probabilities reveal less of

the upward trend made up of those who had only one same-sex partner.

\section{Online Appendix: References}

Bell, Andrew, and Kelvyn Jones. 2014. "Another 'futile quest'? A simulation study of Yang and Land's hierarchical age-period-cohort model." Demographic Research 30(11): 33360 .

—. 2014b. "Don't birth cohorts mater? A commentary and simulation exercise on Reither, Hauser, and Yang's (2009) age-period-cohort study of obesity." Social Science and Medicine 101:176-80.

Glenn, Norval D. 2005. Cohort Analysis. Thousand Oaks, CA: Sage Publications, Inc.

Reither, Eric N., Robert M. Hauser, and Yang Yang. 2009. "Do birth cohorts matter? Ageperiod-cohort analyses of the obesity epidemic in the United States " Social Science and Medicine 69(10):1439-48.

Twenge, Jean M., Ryne A. Sherman, and Brooke E. Wells. 2016. "Changes in American Adults' Reported Same-Sex Sexual Experiences and Attitudes, 1973-2014." Archives of Sexual Behavior DOI 10.1007/S10508-01-0769-4.

Yang, Yang and Keneth C. Land. 2013. Age-period-cohort analysis: New models, methods, and empirical applications. CRC Press.

Yang, Yang, and Kenneth C. Land. 2008. "Age-period-cohort analysis of repeated crosssection surveys: Fixed or random effects?" Sociological Methods \& Research 36(3): $297-$ 326. 